\title{
Planning for Environmental Water Allocations: Hydrology - Based Assessment in the Awash River Basin, Ethiopia
}

\author{
Sisay Teklu* Ahmed H. Soliman Alaa El-Zawahry \\ Irrigation and Hydraulics Department, Faculty of Engineering, Cairo University, Egypt
}

\begin{abstract}
The research is financed by the Egyptian Government through the Nile Sector bilateral cooperation project
\end{abstract} Abstract

With expanding water demand due to rapid socio-economic growth and shrinking supplies due to pollution and climate change impact, there is an increasing strain on the water resources of the Awash river basin. Furthermore, flow alterations due to the existing and the ongoing water resources infrastructure projects may adversely impact the natural life cycle of aquatic ecosystems in the river basin. In order to manage these consequences, compensation releases or allocation of environmental flows may be mandatory and calls for the establishment of environmental flows framework in Ethiopia. In this study, the environmental flows at selected five existing and proposed dam sites in the Awash river basin were investigated using six worldwide used hydrology-based methods, viz.: Desktop Reserve Model (DRM), Global Environmental Flow Calculator (GEFC), Tennant, Tessman, $7 \mathrm{Q}_{10}$ and $\mathrm{Q}_{95}$. The environmental flow volumes from the six methods were compared on mean annual, monthly average and monthly basis and it is found that the predictions from the DRM and GEFC are more reliable than the others. Comparative results indicate that minimum annual average flow rates of $4.4 \mathrm{~m}^{3} / \mathrm{s}(15 \%$ of Mean Annual Flow (MAF)), 10.5 $\mathrm{m}^{3} / \mathrm{s}\left(19 \%\right.$ of MAF), $16.4 \mathrm{~m}^{3} / \mathrm{s}$ ( $22 \%$ of MAF), $2.5 \mathrm{~m}^{3} / \mathrm{s}$ ( $17 \%$ of MAF) and $24.2 \mathrm{~m}^{3} / \mathrm{s}(26 \%$ of MAF) are required at the immediate downstream reaches of Melka kuntre, Koka, Awash Compensation, Kesem and Tendaho dams respectively. Accordingly, the annual average environmental flow throughout the basin varies from $15-26 \%$ of the natural MAF. Although preliminary, being the first attempt in the Awash river basin, this study is expected to stimulate dialogue among experts and decision makers in Ethiopia.

Keywords: EFR, EFA, Tennant, Tessman, Q95, 7Q 10 , DRM, GEFC Software, Awash

DOI: $10.7176 / \mathrm{JEES} / 9-11-08$

Publication date: November $30^{\text {th }} 2019$

\section{Introduction}

The development and utilization of water resources does provide significant benefits to society, particularly through increased and more reliable water supplies, the production of hydropower, and reduced risk of flooding. These benefits must be balanced with the impacts on the natural environment and the various goods and services that rivers provide to society (Speed et al., 2012). This balancing act is being exercised by establishing environmental flows.

According to the Brisbane Declaration (2007), environmental flows (EFs) describe the quantity, timing, and quality of water flows required to sustain freshwater and estuarine ecosystems and the human livelihoods and wellbeing that depend on these ecosystems. The process for determining environmental flows is termed "Environmental flow assessment" or "EFA".

The issues of environmental flow assessment (EFA) and management are high on the world agenda at present. At the same time, it remains a new research field. In many countries, there has not even been a crude nationwide assessment of water requirements of rivers and their associated aquatic ecosystems (Smakhtin and Anputhas, 2006).

In Ethiopia, like other developing nations environmental flow research is new and has not developed very much. The Ethiopian water resources management policy (MoWR, 1999) recognizes basic human and livestock needs as well as the environmental reserve as highest priority water users with regard to water allocation. Despite this provision, there are currently no standard methods on estimation of environmental water requirements (or environmental reserves as it is mentioned in the policy document). Even though, the national water policy makes an emphasis on conservation of aquatic resources and the need of environmental impact assessment, nothing has been mentioned about environmental water requirement and assessment in the policy document. So far there is no standard method or national framework for environmental flows and this fact has led to a situation where riverine ecosystems may not be sustainably preserved across the country.

However, lack of standard method or framework for environmental flows does not mean that the environmental flow component is totally ignored during design and implementation of water resources projects. Some irrigation studies allow $10-15 \%$ of a stream's dry season flow for downstream use and environmental effects (Tiruneh et al., 2013). Even though it lacks scientific grounds, consideration of environmental flows (compensation or down-stream releases) is a common practice during project-level irrigation and hydropower feasibility studies, environmental impact assessments (EIAs) and in reservoir operation simulation studies (EEPCO, 2009, WWDSE, 2005; WWDSE and WAPCOS, 2005).

The only EFR studies done so far in Ethiopia are those by Reitberger and McCartney (2011) and McCartney 
et al. (2008) conducted in the Blue Nile River basin. Reitberger and McCartney (2011) applied three desktop hydrological methods; the Global Environmental Flow Calculator, the Desktop Reserve Model, and the Tennant Method at Karadobi, Didessa and Border proposed dam locations and indicated that $21-28 \%$ of the mean annual flow may be sufficient to sustain basic ecological functioning. McCartney et al. (2008) used the Desktop Reserve Model (DRM) to estimate environmental flow requirements down-stream of the Chara-Chara weir on the Blue Nile River in the reach containing the Falls and indicated that to maintain the basic ecological functioning in this reach requires an average annual allocation of $862 \mathrm{Mm}^{3}$ (i.e. equivalent to $22 \%$ of the mean annual flow).

In highly exploited river system like Awash, there is no question about the need and importance of determining the environmental flow requirement (Tiruneh et al., 2013; WWDSE, 2005). The Awash national park, the conservation areas, the Awash waterfalls, the sites of potential flow alterations (existing and proposed dam sites) and the freshwater terminal lakes are some of the locations of interest for EFA in the Awash river basin. Even though, these sites require site-specific multi-disciplinary comprehensive EFA, in the absence of such studies, hydrology based desktop EFA can be considered as a good start.

There are many methods for determination of EF worldwide which range from rapid to more comprehensive approaches. These methods are grouped into four categories: hydrological, hydraulic rating, habitat simulation, and holistic. Further details on the different EFA methods are provided in (Linnansaari et al., 2013). In data sparse situation where there is limited information on ecology, as is a case of the Awash river basin, methods that utilize purely hydrological data are most appropriate.

The main objective of the present study is to conduct a preliminary environmental flow assessment using desktop hydrology-based methods in order to quantify the environmental flow requirement, which needs to be incorporated into any future water resources development plan and water allocation model of the Awash River basin in Ethiopia. The potential EFs at five selected sites were estimated using six hydrology-based methods, viz.: Desktop Reserve Model (DRM), Global Environmental Flow Calculator (GEFC), Tennant, Tessman, 7Q 10 and 7Q95.

\subsection{Study Area}

Awash basin is situated in east-central Ethiopia and lies between longitude $7^{\circ} 52^{\prime} 12^{\prime \prime} \mathrm{N}$ and $12^{\circ} 08^{\prime} 24^{\prime \prime} \mathrm{N}$, and latitude $37^{\circ} 56^{\prime} 24^{\prime \prime} \mathrm{E}$ and $43^{\circ} 17^{\prime} 24^{\prime \prime} \mathrm{E}$. The Awash River originates from the high plateau to the west of Addis Ababa at an elevation of about 3,000 $\mathrm{m}$ above mean sea level $(\mathrm{msl})$ in the central Ethiopian highlands. It then flows eastwards through the Becho plains along the Rift Valley and terminates in saline Lake Abe at elevation of $250 \mathrm{msl}$ at the border with Democratic Republic of Djibouti (Halcrow, 1989). It has a total area of $114,000 \mathrm{~km}^{2}$ with a total length of $1200 \mathrm{~km}$. The landscape of the basin comprises highlands, escarpment and rift. The main physiographic features of the Awash Basin are the Ethiopian Plateau and the Rift Valley that widens to the north into the Afar Triangle. The annual runoff within the basin is estimated at $4.6 \mathrm{~km}^{3}$ (FAO, 1997). Some tributaries like Mojo, Akaki, Kessem, Kebena and Mile rivers carry water the whole year, while many lowland rivers only function during the rainy seasons. The location map of the Awash River basin is shown in Figure 1.

\subsection{Selection of EFA Sites}

The Awash river basin comprises several water resources development infrastructures and it is important to estimate what amount of water will be released from dams or weirs to downstream reaches in order to protect and maintain the aquatic ecosystem. Accordingly, in the present study five sites of potential flow alterations i.e., sites at the immediate downstream reaches of proposed and existing dams have been selected for environmental flow assessment. The Location and the features of the environmental flow assessment sites are illustrated in Figure 1 and Table 1 respectively. 


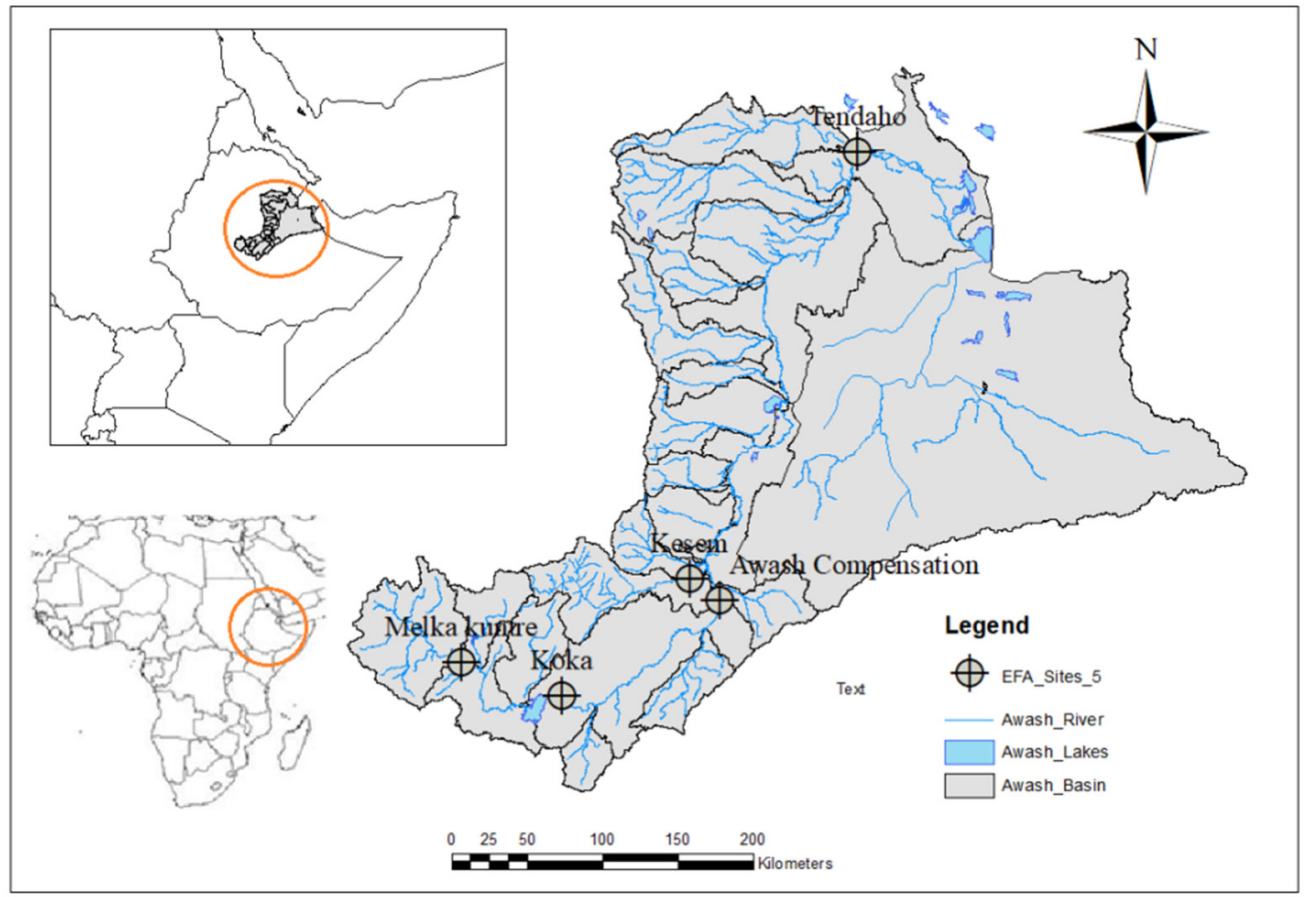

Figure 1: Location Map of the Awash River Basin and Environmental Flow Assessment Sites

\section{Materials and Methods}

\subsection{Data}

Hydrology based desktop assessment of environmental flows requires natural stream flow data at selected sites. The main challenge of hydrology based environmental flow assessment in the Awash river basin is lack of natural flow series. Different approaches have been used to select and define the least modified naturalized flow series for the different EFA sites. Accordingly, for the site EF1 (Melka kuntre) located upstream of Koka dam, the flow data has been considered as the least modified natural flow. For the site EF4 (Kesem), the pre dam data has been used as natural flow. For sites EF2, EF3 and EF5 at Koka, Awash Compensation and Tendaho dams respectively, flow naturalization has been conducted using monthly water balance analysis. Depending on data availability and method of assessment, both daily and monthly data are used at different sites. Daily time series data are used at EF1 and EF4 sites; and for the other sites the analysis is performed using monthly data. The flow duration Index $\left(\mathrm{Q}_{95}\right)$ and low flow index $\left(7 \mathrm{Q}_{10}\right)$ methods are conducted using daily time series data and hence they are applied only for EF1 and EF4 sites. The description of data is presented in Table 1.

Table 1: Geographical Location of the Study Area and Hydrological Data Set

\begin{tabular}{|c|c|c|c|c|}
\hline $\begin{array}{l}\text { EFA } \\
\text { Station } \\
\text { ID } \\
\end{array}$ & Name of Dam & $\begin{array}{l}\text { Gauge Station } \\
\text { Name of the River/ }\end{array}$ & $\begin{array}{l}\text { Geographical } \\
\text { Location }\end{array}$ & Description of Data \\
\hline $\mathrm{EF} 1$ & $\begin{array}{l}\text { Melka kuntre } \\
\text { [Proposed] }\end{array}$ & Awash@Melka kuntre & $\begin{array}{l}8: 42: 0 \mathrm{~N} \\
38: 36: 0 \mathrm{E}\end{array}$ & $\begin{array}{l}\text { Natural daily time series; } \\
\text { Record period: } 35 \text { yrs } \\
(1980-2014)\end{array}$ \\
\hline EF2 & $\begin{array}{l}\text { Koka } \\
\text { [Existing] }\end{array}$ & Awash below Koka dam & $\begin{array}{l}8: 28: 0 \mathrm{~N} \\
39: 10: 0 \mathrm{E}\end{array}$ & $\begin{array}{l}\text { Naturalized monthly time } \\
\text { series; Record period: } 33 \text { yrs } \\
(1968-2000)\end{array}$ \\
\hline $\mathrm{EF} 3$ & $\begin{array}{l}\text { Awash } \\
\text { Compensation } \\
\text { [Proposed] }\end{array}$ & Awash@Awash station & $\begin{array}{l}9: 00: 0 \mathrm{~N} \\
40: 11: 0 \mathrm{E}\end{array}$ & $\begin{array}{l}\text { Naturalized monthly time } \\
\text { series; Record period: } 33 \text { yrs } \\
(1968-2000)\end{array}$ \\
\hline EF4 & $\begin{array}{l}\text { Kesem } \\
\text { [Existing] }\end{array}$ & Kesem@A wara melka & $\begin{array}{l}9: 09: 0 \mathrm{~N} \\
39: 57: 0 \mathrm{E}\end{array}$ & $\begin{array}{l}\text { Natural daily time series; } \\
\text { Record period: } 32 \text { yrs } \\
(1969-2000)\end{array}$ \\
\hline EF5 & $\begin{array}{l}\text { Tendaho } \\
\text { [Existing] }\end{array}$ & Awash@Tendaho & $\begin{array}{l}11: 41: 0 \mathrm{~N} \\
40: 57: 0 \mathrm{E}\end{array}$ & $\begin{array}{l}\text { Naturalized monthly time } \\
\text { series; Record period: } 33 \text { yrs } \\
(1968-2000)\end{array}$ \\
\hline
\end{tabular}

\subsection{Methods}

This study applied from simple $\left(\mathrm{Q}_{95}\right)$ to more advanced desktop method (DRM) hydrology-based methods to 
evaluate the environmental flow in the Awash river basin. The main features of the six EFA methods used in the present study are described below.

2.2.1. Flow Duration Index $\left(Q_{95}\right)$

Flow duration curve (FDC) shows the relationship between magnitude and frequency of flow discharges. Various indices can be extracted from FDC. The flows within a range of 70-99\% time exceedance are usually most widely used as design low flows. The exceedance percentile $\mathrm{Q}_{95}$ can be interpreted as the flow discharge which can be expected to be exceeded $95 \%$ of the time. The $\mathrm{Q}_{95}$ flow has been used as a biological index, for licensing of water takings, and for effluent discharge limits.

2.2.2. Low Flow Index $\left(7 \mathrm{Q}_{10}\right)$

The low flow index $\left(7 \mathrm{Q}_{10}\right)$ method is interpreted as the 7 -day low flow with a 10 year return period using daily discharge data. This method has been applied in various countries as a threshold flow for regulation of water quality from waste water discharges or waste load allocation. Further details on the use of $\mathrm{Q}_{95}$ and $7 \mathrm{Q}_{10}$ indices are provided in (Pyrce, 2004).

2.2.3. Tennant Method

The Tennant method (Tennant, 1976) was developed by the US Fish and Wild Life Service. It assumes some proportion of the average/mean annual flow (MAF) is required to sustain the biological integrity of a river ecosystem. Tennant used stream gauging records to calculate mean annual flow (MAF), and established range of base flow conditions and an associated level of habitat protection on the basis of his qualitative assessment of habitat conditions generated by various flow regimes of streams in Montana. Tennant separated the MAF range into several ecologically important classes which correspond to different levels of aquatic habitat maintenance or degradation and recommended percentage values of MAF for 'low'\&' high' flow season and a periodic flushing flow of $200 \%$ of MAF (Table 2 ).

Table 2: Tennant Method (adapted from Tennant D.L., 1976)

\begin{tabular}{|l|c|c|}
\hline \multirow{2}{*}{ Narrative/ Description of Flows } & \multicolumn{2}{c|}{ Recommended Base Flow Regimes } \\
\cline { 2 - 3 } & Oct.-Mar. & Apr.- Sept. \\
\hline Flushing or Maximum & \multicolumn{2}{|c|}{$200 \%$ of MAF } \\
\hline Optimum Range & \multicolumn{2}{|c|}{$60 \%-100 \% \mathrm{MAF}$} \\
\hline Outstanding & $40 \%$ & $60 \%$ \\
\hline Excellent & $30 \%$ & $50 \%$ \\
\hline Good & $20 \%$ & $30 \%$ \\
\hline Fair or Degrading & $10 \%$ & $30 \%$ \\
\hline Poor or Minimum & $10 \%$ & $10 \%$ \\
\hline Severe Degradation & \multicolumn{2}{|c|}{$<10 \%$} \\
\hline
\end{tabular}

*MAF -Mean Annual Flow

\subsubsection{Tessman Method}

Tessman Method (Tessman, 1980) is a modification of the Tennant method. Tessman's modification was developed to better mimic the annual stream periodicity and avoids over appropriation of flow resulting from a strict application of Tennant's method (KGS Group, 1992). EFR recommendations are made on a monthly basis and incorporate mean monthly flow (MMF) as well as Mean Annual Flow (MAF). Tessman also recommended 14 days period of $200 \%$ of MAF during month of highest runoff for flushing purpose as shown in Table 3.

Table 3: Tessman's Criteria for Determining EFR (adapted from Wilding and Poff, 2008)

\begin{tabular}{|l|c|}
\hline \multicolumn{1}{|c|}{ Situation } & Minimum Monthly Flow (E FR) \\
\hline $1 . \mathrm{MMF}<40 \% \mathrm{MAF}$ & MMF \\
\hline $2 . \mathrm{MMF}>40 \% \mathrm{MAF} \& 40 \% \mathrm{MMF}<40 \% \mathrm{MAF}$ & $40 \% \mathrm{MAF}$ \\
\hline $3.40 \% \mathrm{MMF}>40 \% \mathrm{MAF}$ & $40 \% \mathrm{MMF}$ \\
\hline 14 day period of $200 \% \mathrm{MAF}$ during month of highest runo ff for flushing purpose \\
\hline
\end{tabular}

*MAF -Mean Annual Flow; *MMF -Mean Monthly Flow

2.2.5. Desktop Reserve Model (DRM)

Desktop reserve model (Hughes \& Hannart, 2003) is a hydrology-based model that was originally designed for very rapid and low confidence ecological reserve determinations based on extrapolations from previous, higher confidence, determinations in South Africa. The model was built based on the concepts of the building block method (King and Louw, 1998) and an assumed relationship between the annual water requirements of different category rivers during both normal (referred to as maintenance) years and drought years and an index of hydrological variability. In the model, it is assumed that EFR decreases with increasing flow variability and increases with increasing base flow contribution. The sum of the average coefficient of variation $(\mathrm{CV})$ of flow for the three main months of both the wet and the dry season is used as a measure of flow variability (CV-index). This 
index is then divided by the base flow index (BFI) to give a combined index of flow variability CVB. The CVB index in combination with ecological management category (EMC) parameters were used to develop separate equations for predicting the proportion of low flows and high flows that should constitute EFRs. The model uses four standard EMCs A to D (from "unmodified" to "largely modified") ecosystems and three intermediate EMCs $(\mathrm{A} / \mathrm{B}, \mathrm{B} / \mathrm{C}$ and $\mathrm{C} / \mathrm{D})$. For the frequency component, a set of five parameters for each of 21 pre-determined regions of South Africa define the shapes of non-dimensional monthly assurance rule curves. These curves are defined on the basis of the flow duration curve (FDC) properties of the natural flow regime. The time series of natural monthly flows are used, together with these curves, to generate a representative monthly time series of reserve requirements. Further details of DRM version 2 are provided in (Hughes \& Hannart, 2003).

2.2.6. Global Environmental Flow Calculator

The Global Environmental Flow Calculator (GEFC) is software developed by the International Water Management Institute (IWMI) to support initial quick desktop assessment of environmental flow requirements in river basins. The modeling approach in GEFC includes four main steps. The first step is construction of reference flow duration curves (FDCs) from either default simulated flow time series or user defined monthly time series data. All FDCs are represented by a table of flows corresponding to the 17 fixed percentage points: $0.01,0.1,1,5,10,20,30,40$, $50,60,70,80,90,95,99,99.9$ and $99.99 \%$. The second step is defining the environmental management class (EMC). Six EMCs ranging from A to F (from "unmodified" to "critically modified" ecosystems) and six corresponding default levels of environmental flows have been set in the model. The higher the EMC, the more water is needed for ecosystem maintenance. Given existing conditions and future basin developments, it is possible to estimate EFs corresponding to the best suited / feasible EMC for the river in question. The third step is establishing environmental flow duration curves (FDCs) from reference condition. The software uses the lateral shift approach (Smakhtin and Anputhas, 2006) to determine the default FDC representing a summary of environmental flows (EFs) for each Environmental Management Class (EMC). The last step is simulating continuous monthly time series of EFs using spatial interpolation procedure described in detail by Hughes and Smakhtin (1996). Further details of GEFC approach are provided in (Smakhtin and Eriyagama, 2008).

\subsection{Adjustments to the EFA Methods}

Desktop Reserve Model (DRM) was developed for South Africa regions with parameters values of South Africa rivers. Similarly, Tennant method is developed for temperate zone rivers of USA. Hence, some form of adjustment is necessary to apply these methods in the context of the horn of Africa, in the Awash river basin of Ethiopia.

In the DRM, based on the climate pattern of South Africa, the primary dry season is defined as occurring from June to August and the wet season months are January to March. This assumption cannot be altered within the model. However, the Awash river basin is characterized by a different stream flow pattern, with the wet season mainly from July to September and the dry season flow from December to February. Therefore, the input series should be shifted by six months (i.e., January becomes July, February becomes August, etc.). The output time series will then be corrected accordingly in order to assign the flow values to the appropriate months. Similar approach has been followed by Reitberger and McCartney, 2011 and Karimi et al., 2012. During estimation of EFR component, the DRM user is required to select the monthly distribution type among 22 defined regions of South Africa. Hence, from the database of stream flow parameters of the model, three parameters (annual specific flow, Base Flow Index (BFI) \& hydrologic variability (CV/BFI)) have been used to identify hydrological similarity between the sub-catchments of Awash basin and the regions of South Africa. Considering the Tennant method, recommendations of base flow regimes are based on seasonal distribution of high and low flow patterns of the rivers of USA. Therefore, the seasonal distribution has been adjusted to fit with that of Awash river basin of Ethiopia.

\section{Results and Discussion}

The environmental flow of Awash river basin at the immediate downstream reaches of two proposed (Melka kuntre and Awash Compensation) and three existing (Koka, Kesem and Tendaho) dams has been estimated using six worldwide used hydrology based methods.

As a result, Table 4 shows EF volumes as \% of MAF estimated by the DRM for the seven EMCs from A to $\mathrm{D}$ including the intermediate classes $\mathrm{A} / \mathrm{B}, \mathrm{B} / \mathrm{C}$ and $\mathrm{C} / \mathrm{D}$. As shown in the Table, the higher the class, the more water is allocated for ecosystem maintenance. The DRM EFR values show a variation of $14-16 \%, 21-26 \%$ and $46-$ $67 \%$ of MAF for EMCs D, C and A respectively.

The GEFC EFR results are presented in Table 5. For pristine condition of the river ecosystem (EMC A) EFR varies from 58-80 \% of MAF and for moderately modified river condition (EMC C) EFR shows a variation of 15 - $53 \%$ of MAF. The classes $\mathrm{E}$ and $\mathrm{F}$ indicate a degraded or critically modified condition of a river and they are undesired conditions in river basin management. The EFR values for EMCs E and F are $9 \%$ of MAF or less except site EF5. The GEFC output for site EF2 is illustrated in Figure 2 and from the same figure, comparison of DRM and GEFC outputs shows that DRM is more conservative than GEFC. 
Table 4: EFR using Desktop Reserve Model (DRM)

\begin{tabular}{cccccccccc}
\hline EF & Record & MAF & \multicolumn{4}{c}{ EFR at Different EMCs (\% of MAF) } \\
\cline { 4 - 10 } Station & Period & $\left(\mathrm{m}^{3} / \mathrm{sec}\right)$ & A & A/B & B & B/C & C & C/D & D \\
\hline EF1 & $1980-2014$ & 28.52 & 55 & 45 & 36 & 30 & 24 & 19 & 15 \\
EF2 & $1968-2000$ & 55.40 & 56 & 46 & 37 & 30 & 24 & 19 & 15 \\
EF3 & $1968-2000$ & 75.05 & 48 & 40 & 33 & 27 & 22 & 18 & 14 \\
EF4 & $1969-2000$ & 14.39 & 46 & 39 & 32 & 27 & 21 & 18 & 14 \\
EF5 & $1968-2000$ & 92.56 & 67 & 54 & 42 & 34 & 26 & 21 & 16 \\
\hline
\end{tabular}

Table 5 : EFR using Global Environmental Flow Calculator (GEFC)

\begin{tabular}{ccccccccr}
\hline $\begin{array}{c}\text { EF } \\
\text { Station }\end{array}$ & $\begin{array}{c}\text { Record } \\
\text { Period }\end{array}$ & $\begin{array}{c}\text { MAF } \\
\left(\mathrm{m}^{3} / \mathrm{sec}\right)\end{array}$ & \multicolumn{6}{c}{ EFR $(\%$ of MAF) at Different EMCs } \\
\hline EF1 & $1980-2014$ & 28.52 & 59 & B & C & D & E & F \\
EF2 & $1968-2000$ & 55.4 & 60 & 31 & 15 & 8 & 5 & 3 \\
EF3 & $1968-2000$ & 75.05 & 64 & 38 & 22 & 13 & 8 & 5 \\
EF4 & $1969-2000$ & 14.39 & 58 & 31 & 17 & 10 & 7 & 5 \\
EF5 & $1968-2000$ & 92.56 & 80 & 64 & 53 & 44 & 37 & 32 \\
\hline
\end{tabular}

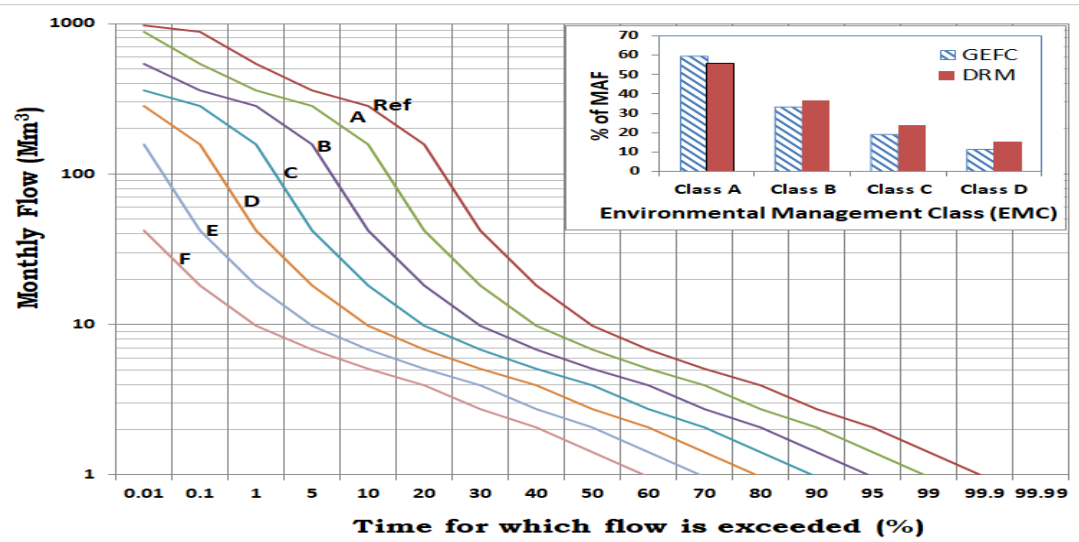

Figure2: GEFC FDC Shifting output and Comparison against DRM Outputs (Site EF2)

The Tennant's method EFR recommendation (Table 6) allocates (40 and 60\% of MAF) and (20 and $40 \%$ of $\mathrm{MAF}$ ) in the low and high flow seasons for outstanding and good habitat conditions respectively. 10\% of MAF in both low and high flow seasons is a threshold for the undesirable poor or minimum habitat condition.

Table 7 shows the Tessman method EFR results. The monthly EFR values show a wide variation with the minimum mostly in January and maximum in August. The EFR varies 5-204\%, 11-202\%, 13-180\%, 16-201\% and 40-84\% for sites EF1, EF2, EF3, EF4 and EF5 respectively.

EFRs using flow duration index $\left(\mathrm{Q}_{95}\right)$ and low flow index $7 \mathrm{Q}_{10}$ are shown in Table 8 . The outputs of the $7 \mathrm{Q}_{10}$ and $\mathrm{Q}_{95}$ methods are presented as a single value. Due to limitations in the availability of natural daily time series flow data, the two methods are applied only for EF1 and EF4 sites. As shown in Table 8, for site EF1, the EFR values are $0.35 \mathrm{~m}^{3} / \mathrm{s}(1.2 \% \mathrm{MAF})$ and $0.66 \mathrm{~m}^{3} / \mathrm{s}(2.3 \% \mathrm{MAF})$ for $7 \mathrm{Q}_{10}$ and $\mathrm{Q}_{95}$ methods respectively, and similarly for site EF4, the EFR values for $7 \mathrm{Q}_{10}$ and $\mathrm{Q}_{95}$ methods are $0.05 \mathrm{~m}^{3} / \mathrm{s}(0.35 \% \mathrm{MAF})$ and $0.19 \mathrm{~m}^{3} / \mathrm{s}(1.3 \% \mathrm{MAF})$ respectively. These flow rates are less than any minimum values calculated by the other four methods.

Table 6: EFR using Tennant Method

\begin{tabular}{|c|c|c|c|c|c|}
\hline \multicolumn{6}{|c|}{ EFR for Different Habitat Conditions ( $\%$ of MAF) } \\
\hline Flushing & Outstanding & Excellent & Good & Fair & Poor or Min \\
\hline $\begin{array}{l}\text { Jul-Sep } \\
200\end{array}$ & $\begin{array}{c}\text { Oct-Jun Jul-Sep } \\
40 \quad 60\end{array}$ & $\begin{array}{c}\text { Oct-Jun Ju1-Sep } \\
30 \quad 50\end{array}$ & $\begin{array}{l}\text { Oct-Jun Jul-Sep } \\
20 \quad 40\end{array}$ & $\begin{array}{c}\text { Oct-Jun Jul-Sep } \\
1030\end{array}$ & $\begin{array}{c}\text { Oct-Jun Jul-Sep } \\
10 \quad 10\end{array}$ \\
\hline
\end{tabular}


Table 7: EFR using Tessman Method

\begin{tabular}{ccccccccccccccccc}
\hline $\begin{array}{c}\text { EF } \\
\text { Secord }\end{array}$ & $\begin{array}{c}\text { MAF } \\
\text { Station }\end{array}$ & \multicolumn{10}{c}{ Period } & (m3/sec) & Jan & Feb & \multicolumn{10}{c}{ Mar. Apr. } & May & Jun & Jul & Aug & Sep & Oct & Nov Dec & Mean \\
\hline EF1 & $1980-2014$ & 28.52 & 5 & 5 & 8 & 14 & 16 & 40 & 99 & 204 & 115 & 40 & 10 & 6 & 47 \\
EF2 & $1968-2000$ & 55.4 & 11 & 13 & 18 & 22 & 21 & 40 & 91 & 202 & 107 & 40 & 19 & 12 & 50 \\
EF3 & $1968-2000$ & 75.05 & 17 & 20 & 29 & 35 & 32 & 38 & 87 & 180 & 110 & 40 & 23 & 13 & 52 \\
EF4 & $1969-2000$ & 14.39 & 16 & 18 & 23 & 21 & 19 & 31 & 101 & 201 & 83 & 40 & 30 & 24 & 51 \\
EF5 & $1968-2000$ & 92.56 & 40 & 40 & 40 & 40 & 40 & 40 & 40 & 84 & 63 & 54 & 40 & 40 & 40 \\
\hline
\end{tabular}

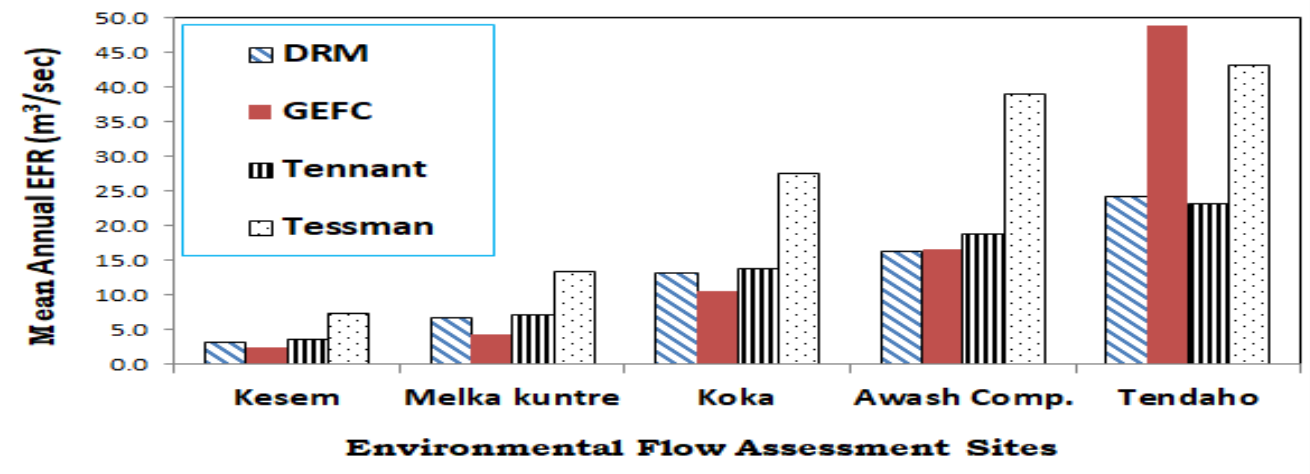

Figure 3: Comparison of the Mean Annual EF estimates using the different methods for EMC C

Based on the above observation of EF volumes, the four methods i.e., Tennant, Tessman, GEFC and DRM were selected for further analysis. The EFR estimates from these methods have different types of output formats. The Tennant's method recommendation is based on a division of the year into two periods (low and high flow months). The Tessman EFR results are based on a division of the year into 12-month periods. In the case of GEFC and DRM, the output is a monthly time series. For comparison purposes the mean annual and the monthly average results of the four methods are shown in figures 3 and 5 respectively. Moreover, the results are summarized in Table 8 following similar approach used by Karimi et al., 2012.

Figure 3 shows a comparison of the mean annual EF volumes estimated by DRM, GEFC, Tennant and Tessman methods. From the figure, it is observed that The EF estimates from Tessman method are high compared to the other alternative methods. The EF volume estimates from DRM, GEFC and Tennant methods are comparable for all the sites except the site EF5. At the site EF5 (Tendaho), the EF estimates from GEFC method is observed to be much higher compared to the other sites. This may be due to the regulation effect of the upstream Gedebassa swamp. From the comparison of flow duration curves (Figure 4), it is observed that the Tendaho site has high minimum flows compared to the other EF sites. Similar highest estimates of EF have been observed for lake-regulated rivers during the global environmental flow assessment (Smakhtin et al., 2004).

A comparison of the monthly average EFR values for site EF1 using GEFC, DRM, Tennant and Tessman methods is shown in Figure 5. From the figure, it is observed that in the high flow season (Jul-Sept.), the highest value of EFR was estimated using Tessman followed by DRM, GEFC and Tennant methods in a decreasing order. However, in the low flow season (Oct-Jun), the highest value of EFR is estimated using the Tennant, Tessman, DRM and GEFC methods in a decreasing order.

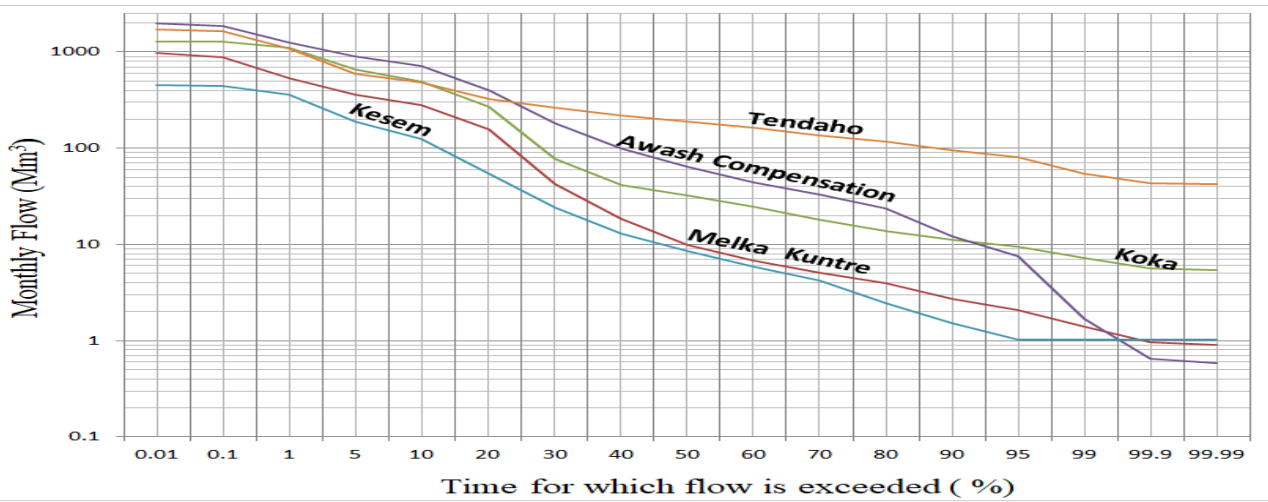

Figure 4: Comparison of Flow Duration Curves 


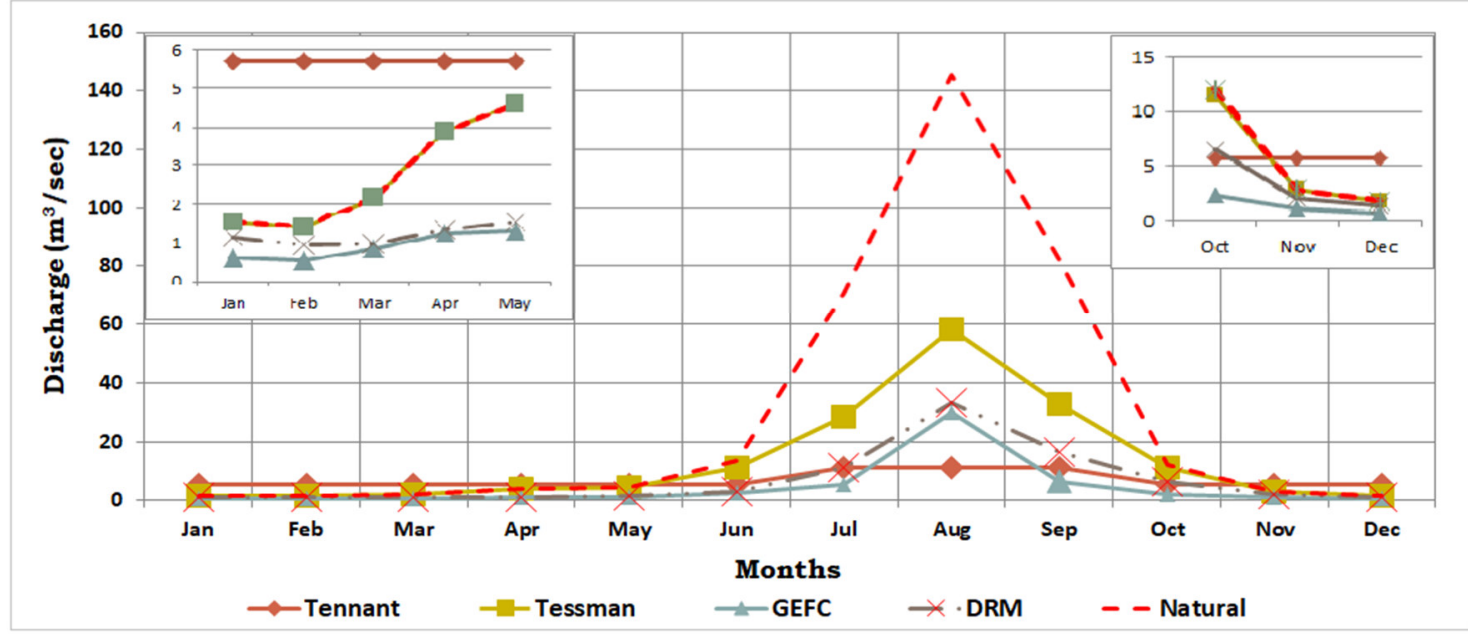

Figure 5: Comparison of Monthly Average EF estimates-EFA Site 1- EMC (C) (Low flow - magnified)

Further investigation has also been conducted on the relationship between the EFR estimates from the four methods (i.e., Tennant, Tessman, DRM and GEFC) and the monthly available flow using plots of EFR versus the period of record monthly natural flow series of the EFA sites. For instance, for site EF1 using EMC-C for GEFC \& DRM and Tennant's good habitat condition, it is observed that for $57 \%$ and $43 \%$ of the total number of months for Tennant and Tessman methods respectively, the EF allocations have been found to be more than the monthly available flows. However, EFRs from GEFC and DRM were less than the monthly flow in the whole period and show a good agreement with the flow pattern of the natural monthly flow. Similar results also observed for the other four sites.

Table 8: Estimation of EFs from Six Hydrological Methods

\begin{tabular}{|c|c|c|c|c|c|c|c|c|c|c|c|}
\hline \multirow{3}{*}{ Method } & \multirow{3}{*}{ Class } & \multicolumn{10}{|c|}{ Environmental Flow Requirement (EFR) } \\
\hline & & \multicolumn{2}{|c|}{$\begin{array}{l}\text { Melka } \\
\text { Kuntre }\end{array}$} & \multicolumn{2}{|c|}{ Koka } & \multicolumn{2}{|c|}{ A wash Comp. } & \multicolumn{2}{|c|}{ Kesem } & \multicolumn{2}{|c|}{ Tendaho } \\
\hline & & $\begin{array}{c}\% \\
\text { MAF }\end{array}$ & $\mathrm{m}^{3} / \mathrm{s}$ & $\begin{array}{c}\% \\
\mathrm{MAF}\end{array}$ & $\mathrm{m}^{3} / \mathrm{s}$ & $\begin{array}{c}\% \\
\text { MAF }\end{array}$ & $\mathrm{m}^{3} / \mathrm{s}$ & $\begin{array}{c}\% \\
\mathrm{MAF}\end{array}$ & $\mathrm{m}^{3} / \mathrm{s}$ & $\begin{array}{c}\% \\
\text { MAF }\end{array}$ & $\mathrm{m}^{3} / \mathrm{s}$ \\
\hline \multirow[t]{6}{*}{ GEFC } & Class A & 59 & 16.9 & 60 & 33 & 64 & 47.7 & 58 & 8.30 & 80 & $\overline{73.6}$ \\
\hline & Class B & 31 & 9.0 & 34 & 18.6 & 38 & 28.6 & 31 & 4.51 & 64 & 59.4 \\
\hline & Class C & 15 & 4.4 & 19 & 10.5 & 22 & 16.6 & 17 & 2.47 & 53 & 48.9 \\
\hline & Class D & 8 & 2.2 & 12 & 6.5 & 13 & 9.8 & 10 & 1.48 & 44 & 40.8 \\
\hline & Class E & 5 & 1.3 & 9 & 4.7 & 8 & 6.1 & 7 & 0.99 & 37 & 34.4 \\
\hline & Class F & 3 & 0.92 & 7 & 3.8 & 5 & 3.9 & 5 & 0.72 & 32 & 29.2 \\
\hline \multirow[t]{7}{*}{ DRM } & Class A & 55 & 15.7 & 56 & 31 & 48 & 35.9 & 46 & 6.67 & 67 & 62.1 \\
\hline & Class A/B & 45 & 12.9 & 46 & 25.4 & 40 & 30.2 & 39 & 5.63 & 54 & 49.9 \\
\hline & Class B & 36 & 10.3 & 37 & 20.3 & 33 & 24.6 & 32 & 4.60 & 42 & 38.9 \\
\hline & Class B/C & 30 & 8.5 & 30 & 16.8 & 27 & 20.6 & 27 & 3.86 & 34 & 31.6 \\
\hline & Class C & 24 & 6.7 & 24 & 13.1 & 22 & 16.4 & 21 & 3.08 & 26 & 24.2 \\
\hline & Class C/D & 19 & 5.5 & 19 & 10.8 & 18 & 13.5 & 18 & 2.53 & 21 & 19.7 \\
\hline & Class D & 15 & 4.3 & 15 & 8.5 & 14 & 10.7 & 14 & 2.01 & 16 & 15.2 \\
\hline \multirow{3}{*}{$\begin{array}{l}\text { Tennant } \\
\text { Good } \\
\text { Condition } \\
\text { Tessman }\end{array}$} & Oct - Jun & 20.0 & 5.7 & 20.0 & 11.1 & 20.0 & 15.0 & 20.0 & 2.9 & 20.0 & 18.5 \\
\hline & Jul - Sept & 40.0 & 11.4 & 40.0 & 22.2 & 40.0 & 30.0 & 40.0 & 5.8 & 40.0 & 37.0 \\
\hline & $\begin{array}{l}\text { Annual } \\
\text { Mean }\end{array}$ & 46.9 & 13.4 & 49.6 & 27.5 & 52 & 39 & 50.5 & 7.3 & 46.8 & 43.3 \\
\hline Q95 & & 2.3 & 0.66 & & & & & 1.3 & 0.19 & & \\
\hline $7 \mathrm{Q} 10$ & & 1.2 & 0.35 & & & & & 0.35 & 0.05 & & \\
\hline $\begin{array}{l}\text { Minimum } \\
\text { Range }(\%\end{array}$ & $\begin{array}{l}\text { Class C } \\
\text { (AF) }\end{array}$ & $\begin{array}{l}15 \\
(15 \\
\end{array}$ & $\begin{array}{c}4.4 \\
-26) \\
\end{array}$ & 19 & 10.5 & 22 & 16.4 & 17 & 2.5 & 26 & 24.2 \\
\hline
\end{tabular}

\section{Conclusion}

Hydrology based environmental flow assessment in the Awash river basin using six worldwide used methods indicated that the Desktop Reserve Model (DRM) and Global Environmental Flow Calculator (GEFC) softwares 
are valid and easy tools for the assessment of environmental flow in the basin. The estimates using flow duration index $\left(\mathrm{Q}_{95}\right)$ and low flow index $7 \mathrm{Q}_{10}$ have been found too low to be recommended as EFR because the results were hardly found to represent even the Tennant' method poor flow condition (10\% of MAF). The result of the methods which are based on the mean annual flow (Tennant and its derivative Tessman) show allocation of EFRs more than the available natural monthly flow during the low flow months. Hence, some form of modification is necessary before applying these methods for the case of Awash river basin.

The predictions of the environmental flow rates from each of the six methods are compared and presented in Table 8. To maintain the basic function of the river ecosystem, the river should be managed within the Class $\mathrm{C}$ or higher ecological level. Comparative results indicate that minimum annual average flow rates of $4.4 \mathrm{~m}^{3} / \mathrm{s}(15 \%$ of MAF), $10.5 \mathrm{~m}^{3} / \mathrm{s}$ (19\% of MAF), $16.4 \mathrm{~m}^{3} / \mathrm{s}$ (22\% of MAF), $2.5 \mathrm{~m}^{3} / \mathrm{s}\left(17 \%\right.$ of MAF) and $24.2 \mathrm{~m}^{3} / \mathrm{s}(26 \%$ of MAF) are required at the immediate downstream reaches of Melka kuntre, Koka, Awash Compensation, Kesem and Tendaho dams respectively. Accordingly, the annual average EF throughout the basin varies from 15-26\% of MAF. Although preliminary and requiring verification through further site-specific ecology-based research, the results provide a credible scientific basis for decision-making on water resources allocation in the Awash river basin.

\section{References}

Brisbane Declaration (2007), "The Brisbane Declaration: Environmental Flows are Essential for Freshwater Ecosystem Health and Human Well-Being", Declaration of the 10th International River symposium and International Environmental Flows Conference. Available online at: https:/www.conservationgateway.org/ConservationPractices/Freshwater/EnvironmentalFlows/MethodsandTools/ELOHA/Page s/Brisbane-Declaration.aspx

EEPCO (2009), "Environmental and Social Impact Assessment of Gibe III Hydropower Project”, Technical Report, Ethiopian Electric Power Corporation, Addis Ababa

FAO (1997), "Irrigation Potential in Africa: A Basin Approach", FAO Land and Water Bulletin 4, Food and Agriculture Organization of the United Nations, Rome, Italy.

Halcrow, W. (1989), "Master Plan for the Development of Surface Water Resources in the Awash River Basin", Volume II, Main Report, Valleys Development Studies Authority (EVDSA), Addis Ababa.

Hughes, DA. \& Hannart, P. (2003), "A desktop model used to provide an initial estimate of the ecological instream flow requirements of rivers in South Africa", Journal of Hydrology 270, 167-181

Hughes, DA. \& Smakhtin, VU. (1996), "Daily flow time series patching or extension: a spatial interpolation approach based on flow duration curves", Journal of Hydrological Sciences 41(6), 851-871

Karimi, SS., Yasi, M. \& Eslamian, S. (2012), "Use of hydrological methods for assessment of environmental flow in a river reach", International Journal of Environmental Science and Technology 9, 549-558.

King, JM. \& Louw, D. (1998), "Instream flow assessments for regulated rivers in South Africa using the building block methodology", Aquatic Ecosystem Health and Restoration 1,109-124

KGS Group and North South Consultants Inc. (1992), "Protection and Restoration of Fish Habitat", A report prepared for the Department of Fisheries and Oceans, Central and Arctic Region, Winnipeg, Manitoba, Canada.

Linnansaari, T., Monk, W.A., Baird, D.J. \& Curry, R.A. (2013), "Review of Approaches and Methods to Assess Environmental Flows Across Canada and Internationally", DFO Canadian Science Advisory Secretariat Research Document-2012/039

McCartney, M., Shiferaw, A. \& Seleshi, Y. (2009), "Estimating Environmental Flow Requirements Downstream of the Chara Chara Weir on the Blue Nile River", Hydrological Processes 23(26), 3751-3758.

MoWR (1999), "Water Resources Management Policy", Policy Document, Ministry of Water Resources, Addis Ababa, Ethiopia.

Pyrce, RS. (2004), "Hydrological Low Flow Indices and Their Uses", WSC Report No.04-2004, Watershed Science Centre, Peterborough, Ontario.

Reitberger, B. \& McCartney, M. (2011), "Concepts of Environmental Flow Assessment and Challenges in the Blue Nile Basin, Ethiopia, in Melese, A.M. (ed), "Nile River Basin Hydrology, Climate and Water Use", Springer Science \& Business Media, Chapter 17, p337-358.

Smakhtin, VU. \& Anputhas, M. (2006), "An assessment of environmental flow requirements of Indian river basins", IWMI Research Report 107, Colombo, Sri Lanka.

Smakhtin, VU. \& Eriyagama, N. (2008), "Developing a software package for global desktop assessment of environmental flows", Environmental Modelling \& Software 23(12), 1396-1406.

Smakhtin, VU., Revenga, C. \& Doll P. (2004), “A pilot global assessment of environmental water requirements \& scarcity", Water International 29, 307-317.

Speed, R., Gippel, C., Bond, N., Bunn, S., Qu, X., Zhang, Y., Liu, W. \& Jiang, X. (2012), “Assessing River Health and Environmental Flow Requirements in Chinese Rivers", International Water Centre Publication, Brisbane, 
Australia

Tiruneh, Y., Berhanu, B., Ayalew, S., Tamrat, I., \& Tesfaye, Y. (2013), “Synthesis report: Awash River Basin Water Audit", FAO and Ministry of Water and Energy, Addis Ababa, Ethiopia.

Tennant, DL. (1976), "Instream Flow Regimes for Fish, Wildlife, Recreation and Related Environment Resources", Fisheries 1(4), 6-10.

Tessman, S.A., (1980), "Environmental Assessment", Technical Appendix E, Environmental Use Sector Reconnaissance Elements of the Western Dakotas Region of South Dakota Study, Water Resources Research Institute, South Dakota State University, Brookings, SD.

Wilding TK, and Poff NL. (2008), "Flow-ecology relationships for the watershed flow evaluation tool", Colo-rado State University. http://www.oregon.gov/owrd/docs/SB839/2008_Wilding_and_Po-ff_Fl-ow_Ecology_Relationships.

WWDSE (2005), “Tendaho Dam and Irrigation Project Design Report”, Water Works Design and Supervision Enterprise (WWDSE), Addis Ababa, Ethiopia

WAPCOS (2005), “Awash River Basin Modelling”, Interim Report, Tendaho Dam and Sugar Project, Water and Power Consultancy Services (WAPCOS), Addis Ababa, Ethiopia. 